\title{
Revealing the Mechanism of Multiwalled Carbon
}

\author{
Nanotube Growth on Supported Nickel
}

Nanoparticles by in Situ Synchrotron X-ray

Diffraction, Density Functional Theory, and

\section{Molecular Dynamics Simulations}

Albert Gili ${ }^{*}, \dot{,}$, Lukas Schlicker ${ }^{\dagger}$, Maged F. Bekheet ${ }^{\dagger}$, Oliver Görke ${ }^{\dagger}$, Delf Kober ${ }^{\dagger}$, Ulla Simon ${ }^{\dagger}$, Patrick Littlewood", Reinhard Schomäcker ${ }^{\S}$, Andrew Doran ${ }^{\perp}$, Daniel Gaissmaier $\|,-,$, Timo Jacob ${ }^{\|, \neg, \text {, Sören Selve }}{ }^{\nabla}$, Aleksander Gurlo ${ }^{\dagger}$

${ }^{\dagger}$ Fachgebiet Keramische Werkstoffe / Chair of Advanced Ceramic Materials, Institut für Werkstoffwissenschaften und-technologien, Technische Universität Berlin, Hardenbergstr. 40, 10623 Berlin, Germany.

$¥$ Center for Catalysis and Surface Science, Department of Chemistry, Northwestern University, Evanston, IL 60208-3113, USA

$\S$ Institut für Chemie, Technische Universität Berlin, Sekretariat TC 8, Straße des 17. Juni 124, 10623 Berlin, Germany 
${ }^{\perp}$ Advanced Light Source, Lawrence Berkeley National Laboratory, Berkeley, California 94720, USA

॥ Institute of Electrochemistry, Ulm University, Albert-Einstein-Allee 47, 89081 Ulm, Germany

$\neg$ Helmholtz-Institute Ulm (HIU) Electrochemical Energy Storage, Helmholtzstr. 11, 89081 Ulm, Germany

『 Karlsruhe Institute of Technology (KIT), P.O. Box 3640, 76021 Karlsruhe, Germany

$\nabla^{\nabla}$ Center for Electron Microscopy (ZELMI), Technische Universität Berlin, Straße des 17. Juni 135, 10623 Berlin, Germany

Corresponding Author

* E-mail Albert Gili: a.gili@ceramics.tu-berlin.de 


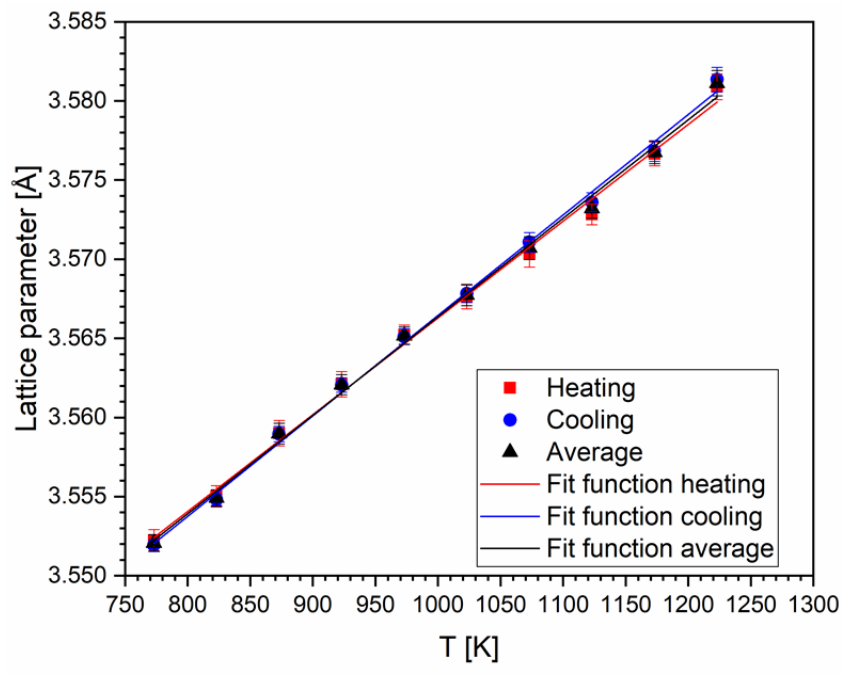

Figure S1. Temperature calibration experiment, showing the lattice parameter obtained from Rietveld refinement as function of the temperature. The $5 \% \mathrm{Ni} / \mathrm{MnO}$ was reduced at $773 \mathrm{~K}$

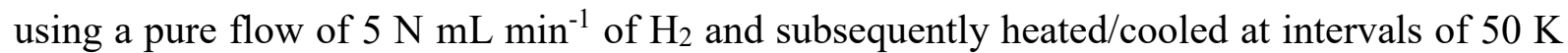
under pure $\mathrm{N}_{2}$ flow. A pattern was acquired at each isotherm upon heating and cooling, and both fittings are included together with its average. 

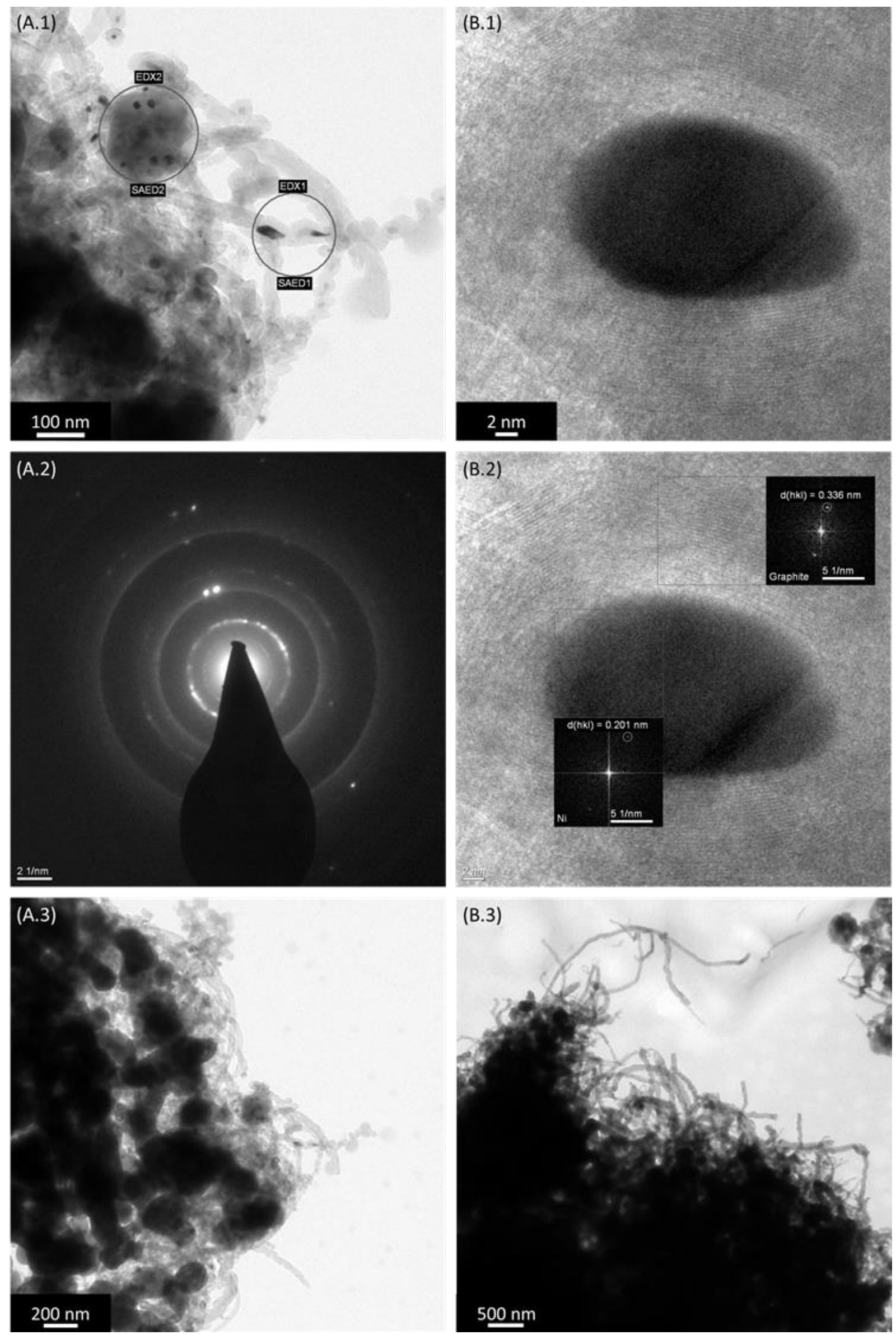
Figure S2. Selected area electron diffraction (SAED) of the $5 \% \mathrm{Ni} / \mathrm{MnO}$ catalysts exposed to $\mathrm{CH}_{4}$ (A) at $873 \mathrm{~K}$ (after $60 \mathrm{~min}$ of TOS with a $\mathrm{CH}_{4}: \mathrm{N}_{2}=1: 1, \mathrm{GHSV}=60000 \mathrm{~L} \mathrm{~h}^{-1} \mathrm{~kg}_{\text {cat }}{ }^{-1}$ ) and (B) $1073 \mathrm{~K}$ (after $120 \mathrm{~min}$ of TOS with a $\mathrm{CH}_{4}: \mathrm{N}_{2}=1: 4, \mathrm{GHSV}=60000 \mathrm{~L} \mathrm{~h}^{-1} \mathrm{~kg}_{\text {cat }^{-1}}$ ). For both temperatures, SAED confirms the graphite (PDF 00-041-1487) and the $f c c$ Ni (PDF 00-0040850) phases. EDX1 analysis in A.1 is not reported. A.3 (873 K) and B.3 (1073 K) display "low" magnification images of the catalyst surface. 
Figure S3 displays the crystallite size of graphite with TOS obtained from refinement of the $873 \mathrm{~K}$ experiment (left panel A) and the $1073 \mathrm{~K}$ experiment (right panel B). The deviation from the expected behavior at $1073 \mathrm{~K}$ (crystallite size change should, if occurring, proceed via crystallite growth) is due to the small initial size of the graphite (200) reflection, combined with two other factors: (1) a small unidentified reflection next to the graphite (200) induce questionable peak fitting, especially when the graphite (200) intensity is small. This peak perturbs the fitting, altering the FWHM values and therefore disguising the real crystallite size. This effect is clearly observed at the end of the experiment during oxidation, when the graphite (002) peak intensity drastically decreased. The second factor (2) is that the obtained crystallite sizes are close to the technique's detection limit $(3 \mathrm{~nm})$ being therefore susceptible to small changes as described above. We can therefore conclude that, for both experiments, the nucleation part of the graphite formation could not be observed and that CNT growth proceeds without crystallite growth. Moreover, the appearance of graphite reflexes does not point to the exact moment in which graphite precipitates but rather highlights that during the exposure time belonging to the pattern under study the amount of graphite above the technique's lower detection limit allowed its first measurement.
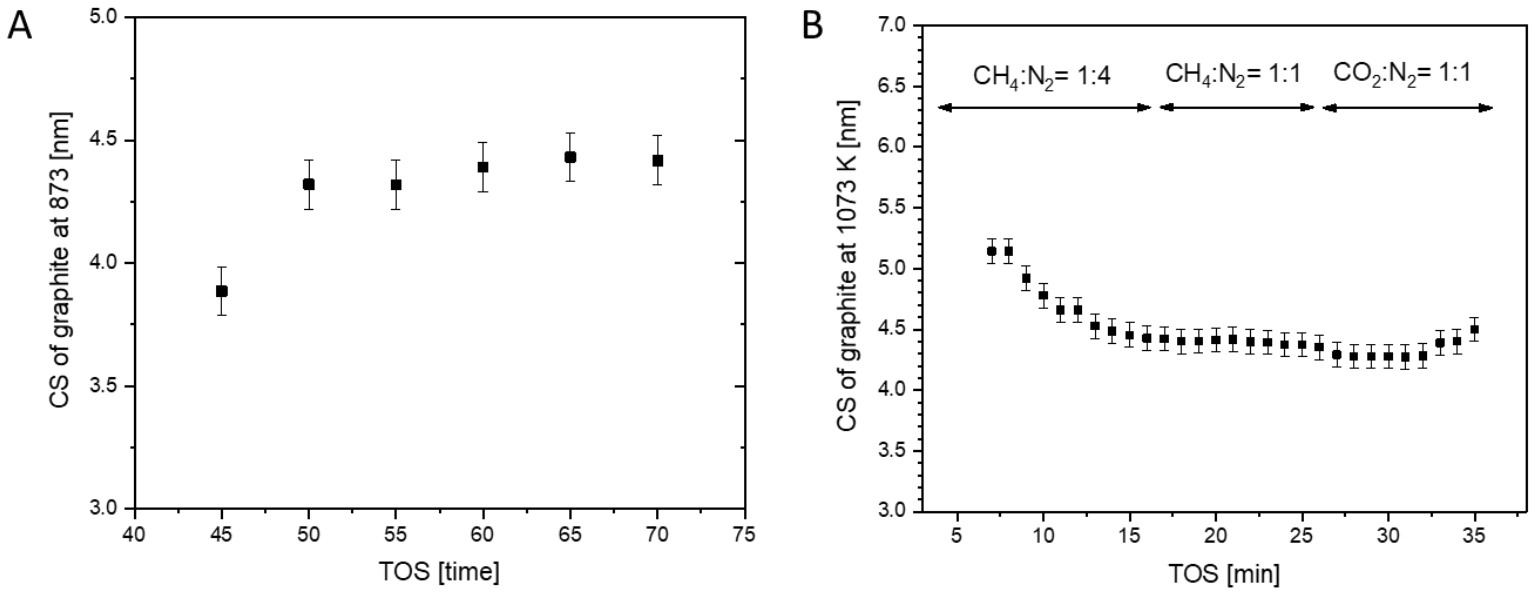

Figure S3. Crystallite size of graphite with TOS at $873 \mathrm{~K}$ (panel A) and $1073 \mathrm{~K}$ experiment (panel B). 
Table S1. Calculated lattice parameters of different $\mathrm{NiC}_{\mathrm{Xi}}$ phases obtained from DFT and ReaxFF simulations. All values are reported in Angstrom. The lattice parameters at $0 \mathrm{~K}$ were derived from the minimum of the equation of state (EOS). In order to study the influence of the temperature on the lattice constant, molecular dynamics simulation (MD) at $873 \mathrm{~K}$ and $1073 \mathrm{~K}$ were carried out. Thereby we found a qualitatively good agreement between the calculated DFT and ReaxFF values.

\begin{tabular}{|c|c|c|c|c|}
\hline \multirow{2}{*}{ Structure } & DFT & ReaxFF & ReaxFF & ReaxFF \\
& $(E O S, 0 \mathrm{~K})$ & $(\mathrm{EOS}, 0 \mathrm{~K})$ & $(\mathrm{MD}, 873 \mathrm{~K})$ & $(\mathrm{MD}, 1073 \mathrm{~K})$ \\
& & 3.612 & 3.643 & 3.652 \\
\hline $\mathrm{Ni}($ bulk) & 3.521 & 3.832 & 3.827 & 3.836 \\
\hline $\mathrm{NiC}_{0.25}$ & 3.733 & 3.942 & 3.953 & 3.961 \\
\hline $\mathrm{NiC}_{0.50}$ & 3.862 & 3.998 & 4.093 & 4.104 \\
\hline $\mathrm{NiC}_{0.75}$ & 3.977 & 4.090 & 4.238 & 4.239 \\
\hline $\mathrm{NiC}^{*}$ & 4.070 & & & \\
\hline
\end{tabular}


Figure $\mathrm{S} 4$ shows the lattice parameter of $\mathrm{Ni}$ as function of the $\mathrm{C} / \mathrm{Ni}$ ratio derived from $\mathrm{ReaxFF}$ calculations at 873 and $1073 \mathrm{~K}$. The initial lattice parameter $(\mathrm{C} / \mathrm{Ni}=0)$ logically increases with increasing amount of $\mathrm{C}$ due to the expansion of the cell unit, being the $1073 \mathrm{~K}$ lattice always greater than the $873 \mathrm{~K}$ one (for a given $\mathrm{C} / \mathrm{Ni}$ ratio) due to thermal expansion.

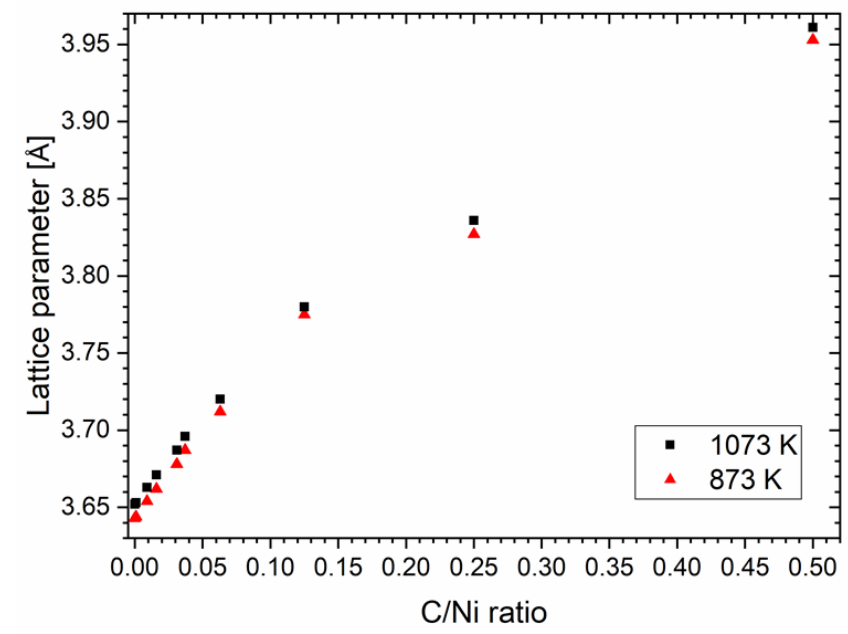

Figure S4. Lattice parameter as function of the $\mathrm{C} / \mathrm{Ni}$ ratio derived from ReaxFF calculations at 873 and $1073 \mathrm{~K}$. 
Figure $\mathrm{S} 5$ shows the increase of the Ni lattice parameter as function of the $\mathrm{C} / \mathrm{Ni}$ ratio derived from ReaxFF simulations (shown in Figure S3) with a $2^{\text {nd }}$ degree polynomial fit at $873 \mathrm{~K}(\mathrm{~A})$ and $1073 \mathrm{~K}(\mathrm{~B})$.
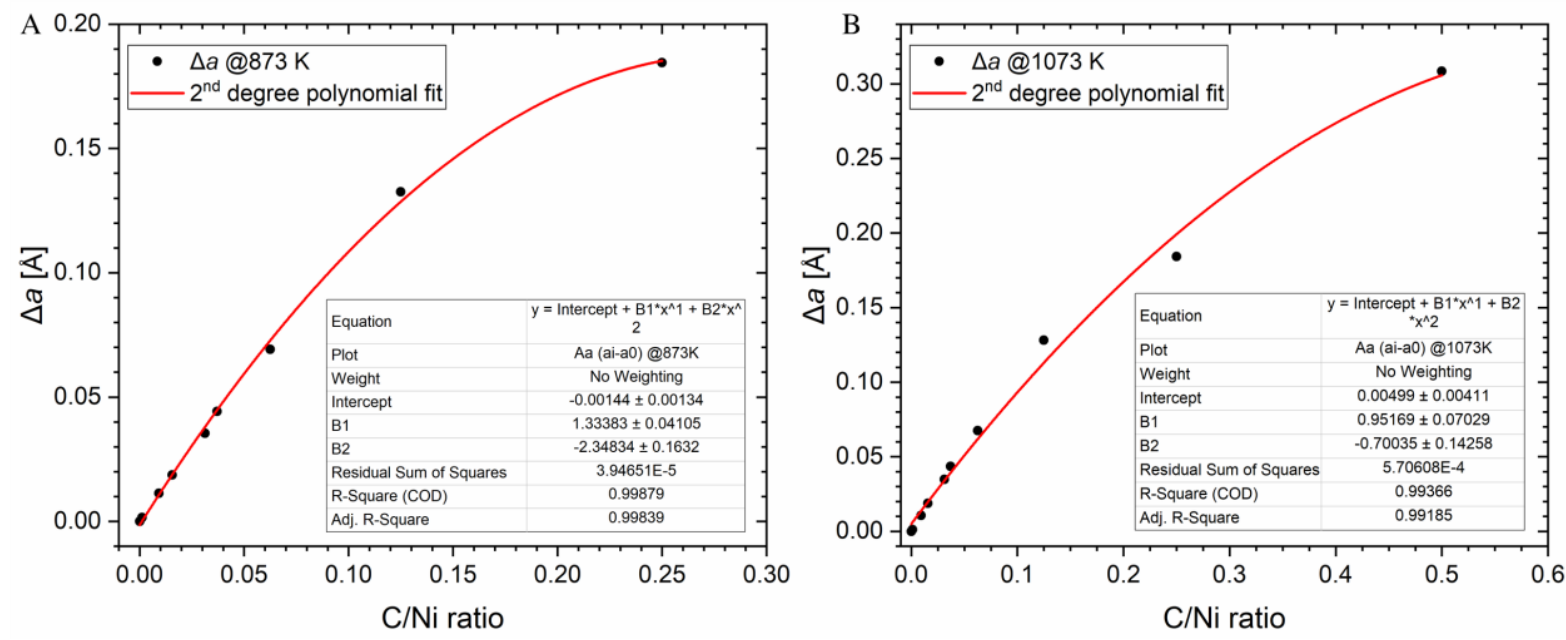

Figure S5. Increase of the Ni lattice parameter as function of the $\mathrm{C} / \mathrm{Ni}$ derived from ReaxFF simulations and polynomial fit at (A) $873 \mathrm{~K}$ and (B) $1073 \mathrm{~K}$. 
Table S2. Lattice parameters of the $\mathrm{NiC}_{\mathrm{Xi}}$ phases obtained from peak fitting of the CVD experiment at $1073 \mathrm{~K}$ shown in Figure 6.

\begin{tabular}{|c|c|c|c|c|c|}
\hline TOS & Gas & $\begin{array}{l}\text { Phase1: } \\
\text { Ni }\end{array}$ & $\begin{array}{c}\text { Phase2: } \\
\text { NiC }_{X 1}\end{array}$ & $\begin{array}{l}\text { Phase3: } \\
\text { NiCX } 2\end{array}$ & $\begin{array}{l}\text { Phase4: } \\
\text { NiC }_{X 3}\end{array}$ \\
\hline $\min$ & {$[-]$} & $\AA$ & $\AA$ & $\AA$ & $\AA$ \\
\hline 1 & \multirow{16}{*}{ 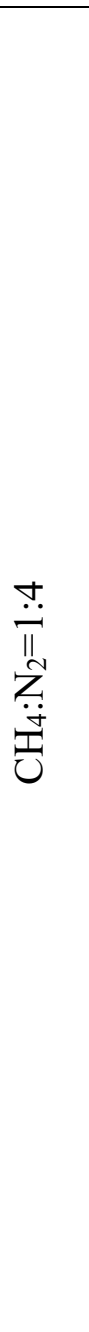 } & 3.565 & - & - & - \\
\hline 2 & & 3.565 & - & - & - \\
\hline 3 & & 3.565 & - & - & - \\
\hline 4 & & 3.568 & 3.613 & 3.736 & 3.798 \\
\hline 5 & & - & 3.618 & 3.725 & 3.776 \\
\hline 6 & & - & 3.619 & 3.724 & 3.769 \\
\hline 7 & & - & 3.617 & 3.722 & 3.755 \\
\hline 8 & & - & 3.616 & 3.723 & 3.750 \\
\hline 9 & & - & 3.614 & 3.733 & - \\
\hline 10 & & - & 3.613 & 3.733 & - \\
\hline 11 & & - & 3.611 & 3.732 & - \\
\hline 12 & & - & 3.610 & 3.730 & - \\
\hline 13 & & - & 3.609 & 3.728 & - \\
\hline 14 & & - & 3.608 & 3.728 & - \\
\hline 15 & & - & 3.607 & 3.728 & - \\
\hline 16 & & - & 3.607 & 3.728 & - \\
\hline 17 & \multirow{7}{*}{ 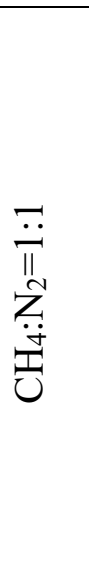 } & - & 3.606 & 3.728 & - \\
\hline 18 & & - & 3.604 & 3.726 & - \\
\hline 19 & & - & 3.597 & - & - \\
\hline 20 & & - & 3.598 & - & - \\
\hline 21 & & - & 3.604 & - & - \\
\hline 22 & & - & 3.606 & - & - \\
\hline 23 & & - & 3.606 & - & - \\
\hline
\end{tabular}




\begin{tabular}{|c|c|c|c|c|c|}
\hline 24 & \multirow{12}{*}{$\begin{array}{l}\underset{\pi}{\pi} \\
\underset{\sim}{\pi} \\
\ddot{\tilde{C}} \\
\stackrel{0}{U}\end{array}$} & - & 3.606 & - & - \\
\hline 25 & & - & 3.609 & - & - \\
\hline 26 & & - & 3.614 & - & - \\
\hline 27 & & 3.578 & - & - & - \\
\hline 28 & & 3.571 & - & - & - \\
\hline 29 & & 3.570 & - & - & - \\
\hline 30 & & 3.570 & - & - & - \\
\hline 31 & & 3.570 & - & - & - \\
\hline 32 & & 3.569 & - & - & - \\
\hline 33 & & 3.568 & - & - & - \\
\hline 34 & & 3.567 & - & - & - \\
\hline 35 & & 3.567 & - & - & - \\
\hline
\end{tabular}


Figure S6 shows the in situ XRD patterns of a CNT growth experiment on the $5 \% \mathrm{Ni} / \mathrm{MnO}$ catalyst at different temperatures. After catalyst reduction as usual, a pure $\mathrm{CH}_{4}$ flow at $873 \mathrm{~K}$ and GHSV $=300000 \mathrm{~L} \mathrm{~h}^{-1} \mathrm{~kg}_{\mathrm{cat}}{ }^{-1}$ has been used to generate graphite. Once graphite reflexes are observed, the setup is cooled down stepwise to 773,673 and $573 \mathrm{~K}$ with cooling rates of $0.5 \mathrm{~K}$ $\mathrm{s}^{-1}$ and isotherm periods of $10 \mathrm{~min}$ at each reaction temperature under constant $\mathrm{CH}_{4}$ flow. It must be stated that clear differentiation of Ni metal and its carbide forms is not easy, due to similar distances of the $\mathrm{Ni}(111)$ and the $\mathrm{Ni}_{3} \mathrm{C}(113)$ planes ${ }^{1}$. Moreover, in nanoparticles, the small-size effect may result in some lattice distortion ${ }^{2}$, adding extra difficulty to metal-metal carbide differentiation. Our results show that no bulk formation of Ni carbide $\left(\mathrm{Ni}_{3} \mathrm{C}\right.$ PDF 01 072-1467 or $\mathrm{NiC}_{\mathrm{x}}$ PDF 00-045-0979 ${ }^{3}$ ) occurs at any reaction temperature. This observation agrees with other authors results, who reported absence of bulk $\mathrm{Ni}_{3} \mathrm{C}$ during M-/FLG (mono and few-layer graphene) $\mathrm{CVD}$ of $\mathrm{C}_{2} \mathrm{H}_{2}$ at $823 \mathrm{~K}^{4}$. A phase transformation of bulk $\mathrm{Ni}_{3} \mathrm{C}$ to $f c c$ Ni has also been reported at $573 \mathrm{~K}$, matching our experimental observation of lack of bulk $\mathrm{Ni}_{3} \mathrm{C}$ at this temperature ${ }^{5}$. Nevertheless, our results disagree with previously reported ex situ XRD data ${ }^{6}$. 


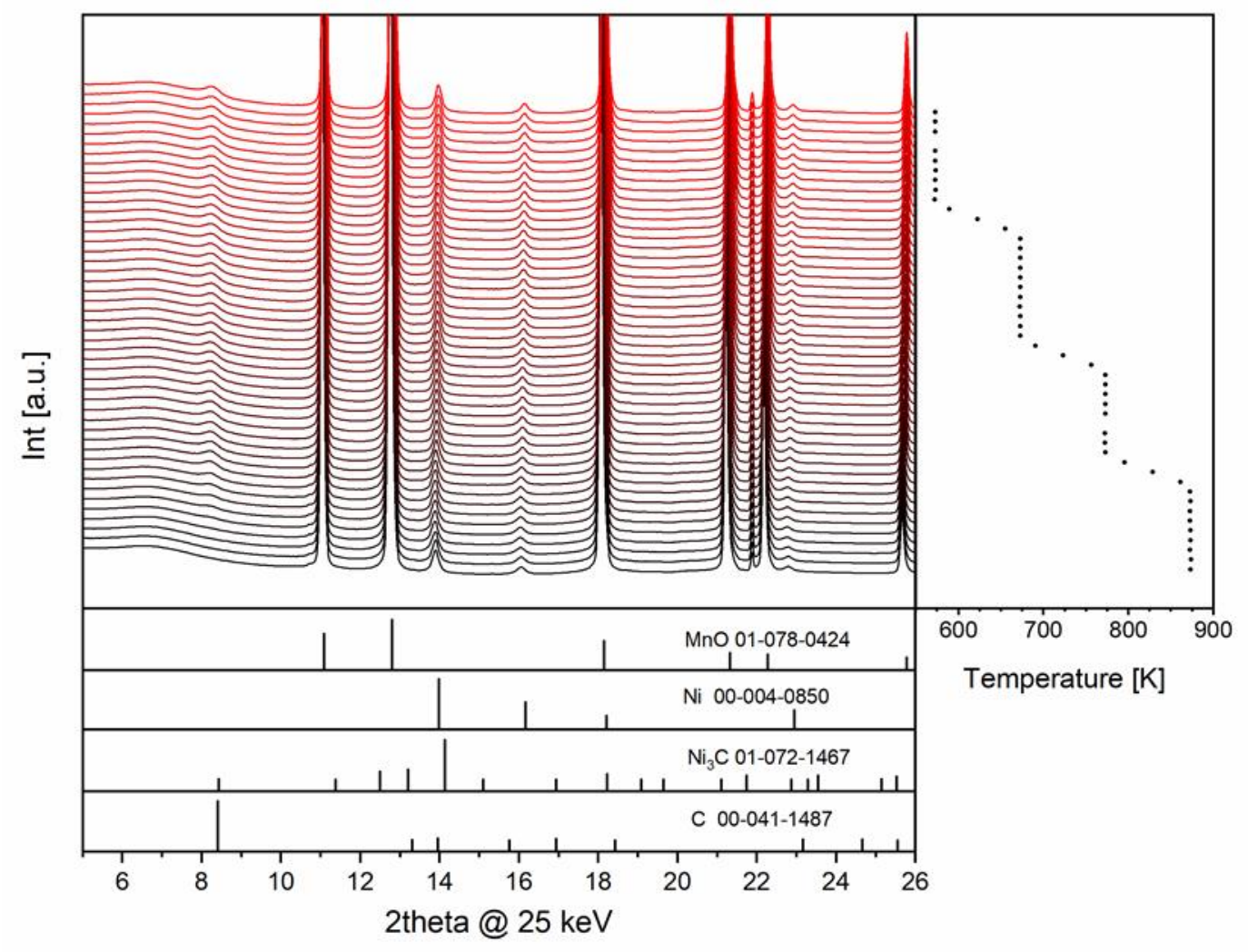

Figure S6. In situ XRD patterns of the 5\% Ni/MnO catalyst during CNT growth at 873-573 K under constant pure $\mathrm{CH}_{4}$ flow $\left(\mathrm{GHSV}=300000 \mathrm{~L} \mathrm{~h}^{-1} \mathrm{~kg}_{\mathrm{cat}}{ }^{-1}\right)$. A pattern was obtained at $70 \mathrm{~s}$ intervals. The XRD patterns are stacked and progressively turn from black to red with TOS (bottom to top). The right panel displays the reaction temperature. 


\section{References}

(1) Wirth, C. T.; Hofmann, S.; Robertson, J. State of the catalyst during carbon nanotube growth. Diamond Relat. Mater. 2009, 18, 940-945.

(2) Yellampalli, S. Carbon Nanotubes - Synthesis, Characterization, Applications; InTech, 2011.

(3) Zhao, Y.-X.; Bowers, C. W.; Spain, I. L. Graphitic nature of chemical vapor-deposited carbon filaments grown on silicon surfaces from acetylene. Carbon 1988, 26, 291-293.

(4) Weatherup, R. S.; Bayer, B. C.; Blume, R.; Baehtz, C.; Kidambi, P. R.; Fouquet, M.; Wirth, C. T.; Schlögl, R.; Hofmann, S. On the mechanisms of Ni-catalysed graphene chemical vapour deposition. ChemPhysChem 2012, 13, 2544-2549.

(5) Bayer, B. C.; Bosworth, D. A.; Michaelis, F. B.; Blume, R.; Habler, G.; Abart, R.; Weatherup, R. S.; Kidambi, P. R.; Baumberg, J. J.; Knop-Gericke, A.; Schloegl, R.; Baehtz, C.; Barber, Z. H.; Meyer, J. C.; Hofmann, S. In Situ Observations of Phase Transitions in Metastable Nickel (Carbide)/Carbon Nanocomposites. J. Phys. Chem. C 2016, 120, 2257122584.

(6) Yu, B.; Zhang, Q.; Hou, L.; Wang, S.; Song, M.; He, Y.; Huang, H.; Zou, J. Temperaturedependent chemical state of the nickel catalyst for the growth of carbon nanofibers. Carbon 2016, 96, 904-910. 